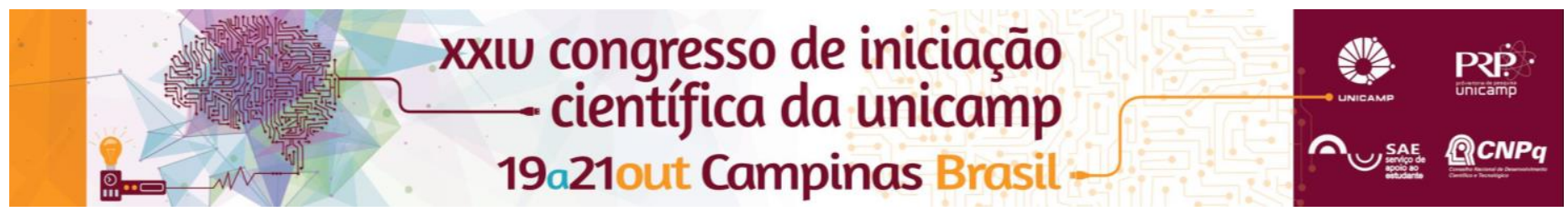

\title{
The Influence of Migration on the Socio-Spatial Restructuring of the Metropolitan Region of Fortaleza
}

\section{Suyanne Galvão Bacelar*}

\begin{abstract}
In this research it is presented a demographic analysis, it was investigated the function of the migration in the formation process and urban expantion of the Metropolitan Region of Fortaleza (MRF) and its social-spatial segregation process between the decades of 1990, 2000 and 2010. Thus, this work checks the function of migration in the configuration of the center and the periphery into the MRF, analysing which are the causes and the consequences for the urban processes and already pointing for the social-spatial segregation of the population. Involving the following objectives: analyse and discuss the relation center-periphery into the MRF, as well as the validity nowadays of this pattern in the region; understand the aspects of social-spatial segregation, especially in its demographic dimension; analyse if the function of the migration has changed over time, furthermore, between the decades of 1990 and 2000; and, reflect on the lack of public policies for the people of lower classes in this region.
\end{abstract}

\section{Key words: \\ Migration, Urban Sprawl, Metropolitan Region of Fortaleza.}

\section{Introduction}

This paper proposes to identify the function of migration in the formation and expansion of the Metropolitan Region of Fortaleza. Thus, it was verified the function of migration in the center and periphery configuration in the MRF and it was investigated what were the causes and consequences, already highlighting the socio-spactial segregation of the population. It had as objectives: to analyze and discuss the center-periphery relationship in MRF, as well as the validity today of this pattern in the region; to analyse and the tendences ans caracteristics of migration in the decades of 1990 and 2000; to understand the aspects of socio-spatial segregation, particularly in its demographic dimension; and to reflect on the lack of public policies for the people of the lower socioeconomic classes in this region.

\section{Results and Discussion}

The methods used for the study of this theme were bibliographic research and organization of the census data for the years 1991, 2000 and 2010. Besisdes the population volumes based on this source, it can be captured not only the migration by modalities and for fiveyear periods $1986 / 1991,1995 / 2000$ and $2005 / 201$, as the socioeconomic characteristics of migrants. It was verified that the production of space in the MRF is oriented, practically, by the capitalist housing market, which, in turn, is articulated by the interests of the class of entrepreneurs and high socioeconomic classes. This phenomenon highlights the socio-spatial segregation, being a product of disputes by location in city ${ }^{1}$. From Figure 1 , it is noted that there was a more intense growth of the peripheral municipalities of MRF. Aggregated data also show that the highest percentage of population with low education are on the periphery. Seen from the migration phenomenon, especially the intra-metropolitan character, it is observed that Fortaleza regularly presented in the three periods analyzed, the increased flow of emigrants and Caucaia the largest influx of immigrants. Regarding the data, it was found that the largest portion of MRF of immigrants are between 15 and 59 years old, in all municipal categories (polo, subpolo, near and distant periphery traditional traditional periphery) and the Census observed. Also noteworthy is that there was a general increase in education, however, is attributed to this indicator, the region, a pattern of selectivity, since the higher education levels are in the municipalities of greater economic development.

Image 1. Average annual population growth rate of cities. Metropolitan Region of Fortaleza, 1991/2000 and 2000/2010

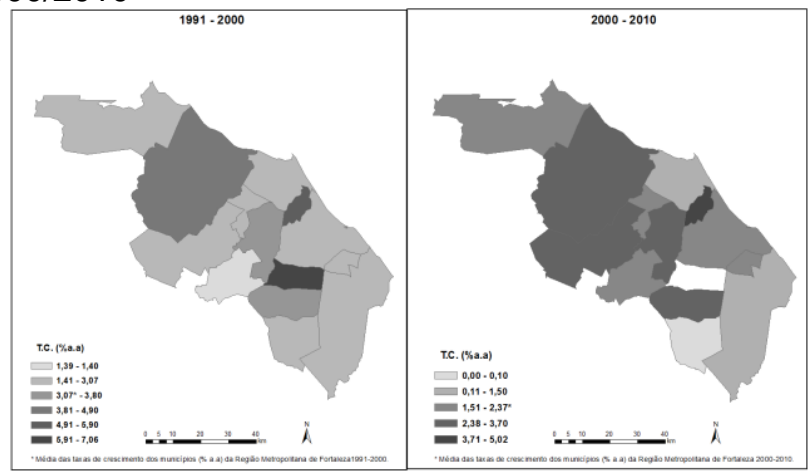

Source: IBGE, Demographic Census in 2000 and 2010 (elaboration NEPO / UNICAMP, Trajectories Project).

\section{Conclusions}

It is considered notorious the explicit continuity in the data expressing metropolitan dynamics between the decades of 1990 and 2010, as migration flows. It is concluded that the largest portion of migrants in this metropolitan area is part of the economically active population and there was a relative improvement in the education of people migrating.

\section{Acknowledgement}

I thank my advisor, prof. dr. José Marcos Pinto da Cunha, who was present and available in the collaboration of this research, in addition, he provided incentives in the preparation and the development of this work and provided theoretical resources for the progress of the research. I also thank CNPq for giving me the opportunity to research this object that was of great academic growth.

1 VILLAÇA, Flávio. Espaço intra-urbano no Brasil. São Paulo: Studio Nobel FAPESP: Lincoln Institute, 1998. 